\title{
A scanning force microscopy study on the morphology of elastomer-coagent blends
}

\author{
H. G. Dikland, S. S. Sheiko*, L. van der Does, M. Möller* and A. Bantjes \\ Department of Chemical Technology, Polymer Materials Section, University of Twente, \\ PO Box 217, 7500 AE Enschede, The Netherlands \\ (Received 14 July 1992; revised 15 October 1992)
}

\begin{abstract}
Atomic force scanning microscopy (AFM) was used to investigate the dispersion of low molecular weight compounds in ethylene-propylene copolymers (EPM). Where other microscopical techniques failed to provide morphological details of this type of blend, as a result of the restricted resolution (light microscopy) or the volatility of the low molecular weight component (SEM), the AFM technique provided surface images, which show inclusions in the matrix of the uncrosslinked polymers.
\end{abstract}

(Keywords: atomic force microscopy; peroxide vulcanization; ethylene-propylene rubber; coagent dispersion)

\section{INTRODUCTION}

In peroxide vulcanization of ethylene-propylene copolymers (EPM), coagents are used for improvement of the crosslinking efficiency ${ }^{1,2}$. Although these multi-unsaturated low molecular weight compounds are widely used, a detailed insight of how coagents enhance the crosslink density during peroxide vulcanization is still lacking.

As part of our study on the mechanism of peroxide vulcanization of $\mathrm{EP}(\mathrm{D}) \mathrm{M}$ elastomers, we investigated the reactions of dimethacrylate-terminated ethyleneglycols (e.g. triethyleneglycoldimethacrylate; TriEDMA) during an EPM peroxide cure ${ }^{3}$. Results from $F T$ i.r. spectroscopy and swelling experiments indicated a dispersed nature of the elastomer-coagent system. However, common microscopical techniques failed to characterize these blend structures adequately, due to restricted resolution of the technique (light microscopy) or the volatility of the coagent (SEM)

In the present communication we report for the first time on the use of AFM for imaging unvulcanized elastomer-coagent surfaces, in order to monitor the dispersion of the coagent. This technique demonstrates high morphological contrast and runs at atmospheric conditions, and in unusual cases it offers atomic resolution $^{4-9}$. Studies were directed at the morphology of samples as compounded for the final curing step.

\section{EXPERIMENTAL}

\section{Materials}

EPM (Vistalon 606, Exxon Chemicals, Belgium, $48 \mathrm{wt} \%$ ethylene, $M_{\mathrm{n}}$ (g.p.c.-d.r.i.) $=97000 \mathrm{~g} \mathrm{~mol}^{-1}$ ) was precipitated from $\mathrm{n}$-hexane in methanol. TriEDMA (ATM 2, Ancomer Ltd, UK) was used as received. Dicumylperoxide (DCP) (Perkadox BC, Akzo Chemicals, The Netherlands) was purified by recrystallization from methanol.

\footnotetext{
* To whom correspondence should be addressed
}

\section{Sample preparation}

The coagent and $2 \mathrm{wt} \%$ peroxide were dissolved in a $5 \%$ solution of EPM in $n$-hexane, followed by pouring the solution into a Petri dish. After the hexane was evaporated completely ( $\sim 90 \mathrm{~min})$, the compound film was transferred in a small copper ring $(2 \mathrm{~mm}$ thick, i.d. $=5 \mathrm{~mm})$ and pressed between brass sheets $(10 \mathrm{MPa}$, $\left.100^{\circ} \mathrm{C}, 60 \mathrm{~s}\right)$. The cylindrical sample was removed from the ring and used for AFM measurements.

\section{AFM measurements}

Micrographs were recorded with a Nanoscope II microscope (Digital Instruments, Inc., Santa Barbara, CA, USA). A V-shaped cantilever with a length of $200 \mu \mathrm{m}$, an $\mathrm{Si}_{3} \mathrm{~N}_{4}$ pyramidal tip and a spring constant of $0.06 \mathrm{~N} \mathrm{~m}^{-1}$, was used for the measurements. EPM surfaces were imaged at a constant force. The sample was moved in the $x-y$ plane and a voltage was applied, which moved the piezo driver - on top of which the compound sample was placed - over the $z$-axis, in order to keep the probing force constant, resulting in a threedimensional height image of the examined surface. The force applied to the samples was as small as possible, because of the softness of unvulcanized rubber. The force was typically kept at $5 \mathrm{nN}$.

\section{RESULTS AND DISCUSSION}

A two-dimensional surface image of a compound mixture is shown in Figure 1. It demonstrates the presence of apparent cavities, regularly distributed over a flat matrix. Figure 2 shows more detailed surface images of compound mixtures, containing 0,3 and $6 \mathrm{wt} \%$ TriEDMA. The surface of the pure elastomer is relatively flat, whereas the blends show irregularly shaped cavities, increasing in size when the coagent concentration was increased.

Two explanations for the observed 'cavities' can be proposed. In the first instance, the surface topography may be influenced by differences in the surface energy of 


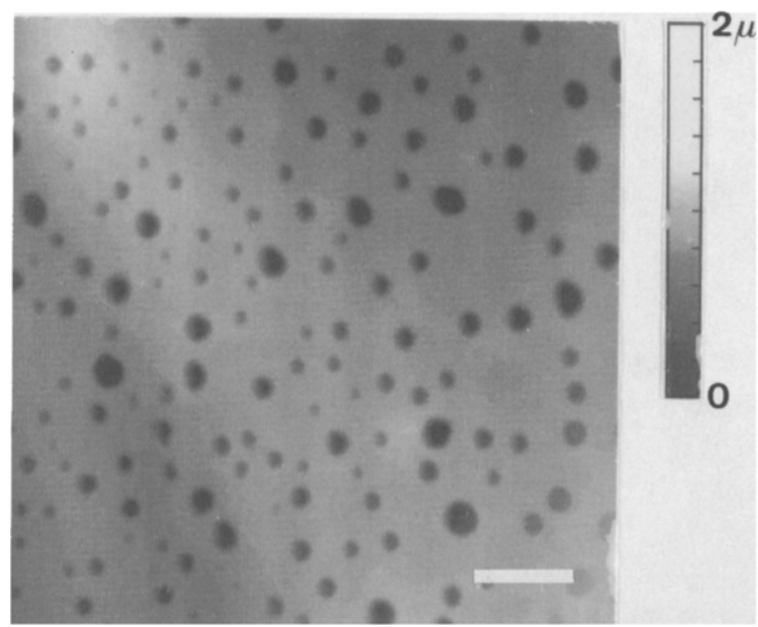

Figure 1 AFM two-dimensional height surface image (constant force) of an EPM-TriEDMA-DCP blend, containing $3 \mathrm{wt} \%$ of the coagent, heated at $100^{\circ} \mathrm{C}(60 \mathrm{~s})$; scanned area $119 \times 119 \mu \mathrm{m}^{2}$. Scale bar $=12 \mu \mathrm{m}$; the black and white bar indicates a scale in the $z$-direction
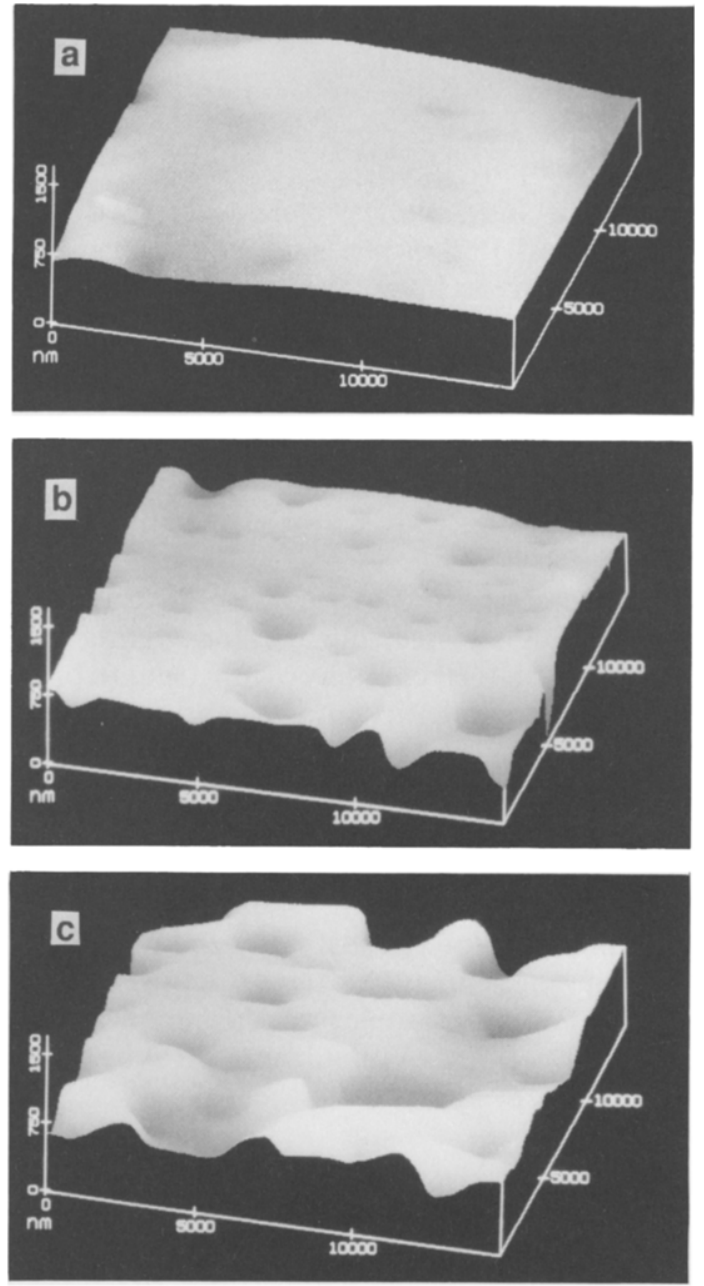

Figure 2 AFM three-dimensional height surface images of EPM TriEDMA-DCP blends, heated at $100^{\circ} \mathrm{C}(60 \mathrm{~s})$; scanned area $15.6 \times 15.6 \mu \mathrm{m}^{2}$ : (a) $0 \mathrm{wt} \%$ coagent, $2 \mathrm{wt} \%$ DCP; (b) $3 \mathrm{wt} \%$ coagent, $2 \mathrm{wt} \%$ DCP; (c) $6 \mathrm{wt} \%$ coagent, $2 \mathrm{wt} \%$ DCP

the coagent and the elastomer phase. Surface activity and phase separation arrested by concurrent crosslinking was observed to result in changes of the surface relief ${ }^{9}$. In this case AFM shows a realistic three-dimensional profile of the surface. Another likely explanation might be a difference in compliance of the blend components. The relatively soft nature of the coagent might allow tip penetration into the sample, thus resulting in the observed 'cavities'. Both explanations imply selectivity of the scanning probe towards the different compound components.

Despite the obvious concentration dependence (Figure 2), the interpretation of the figures, as evidence for a dispersion of coagent droplets in the elastomer matrix, can be questioned in view of possible artifacts, such as surface modification by the scanning tip. An example of this is shown in Figure 3. An asymmetric membrane of polysulfone had been scanned with different probing forces. The results demonstrate that a high force created artificial nodules and pores, whereas a lower force provided a finer structure image. However, with
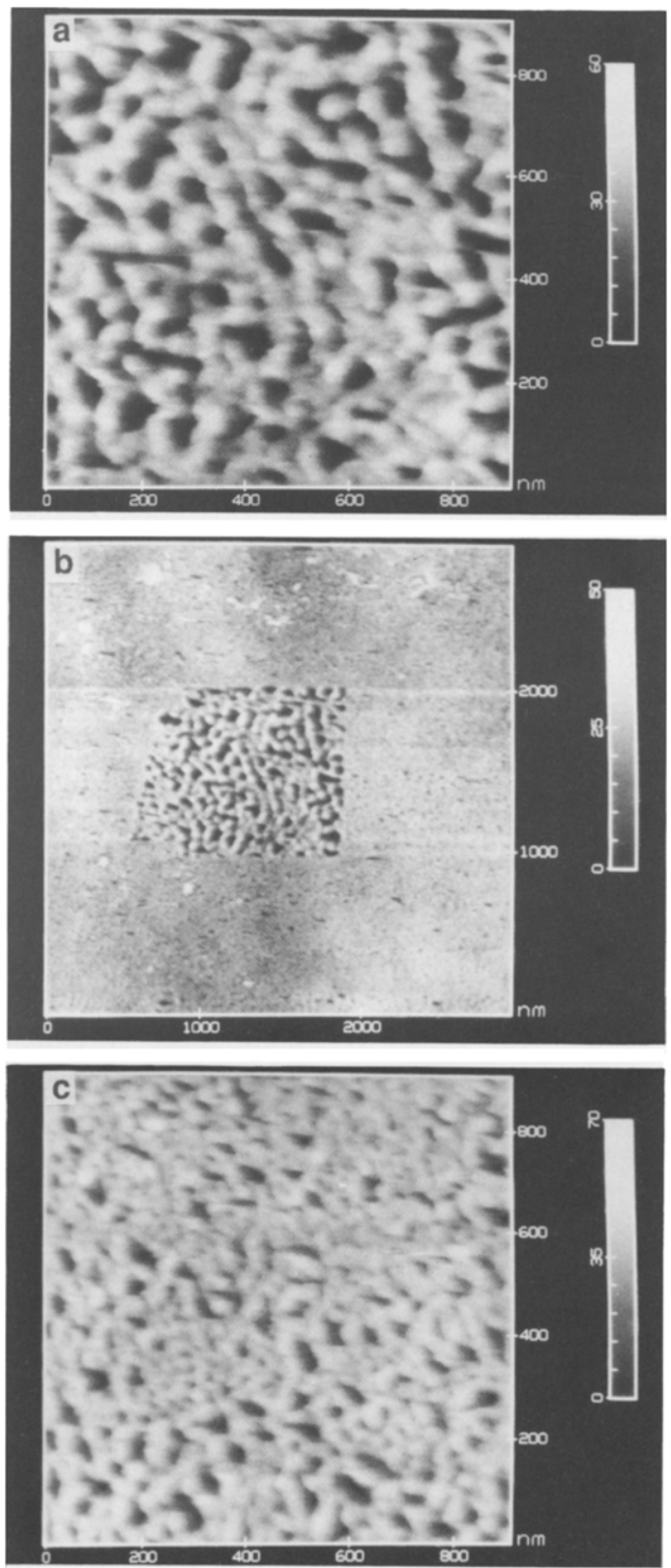

Figure 3 AFM two-dimensional height micrographs of solution-cast polysulfone membranes, recorded successively with different probing forces: the black and white bars indicate a scale in the $z$-direction: (a) scanned area $1 \times 1 \mu \mathrm{m}^{2}$; probing force $20 \mathrm{nN}$; (b) scanned area $3 \times 3 \mu \mathrm{m}^{2}$; probing force $4 \mathrm{nN}$, including the scanned area of Figure $3 a$ : (c) another $1 \times 1 \mu \mathrm{m}^{2}$ area as in (a), but scanned with less damaging force; probing force $4 \mathrm{nN}$ 


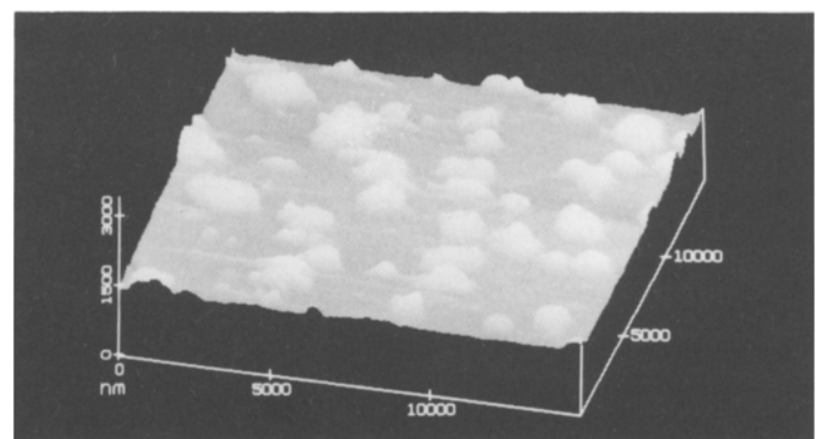

Figure 4 Three-dimensional AFM height micrograph of an EPMcoagent blend, containing $2 \mathrm{wt} \%$ DCP and $3 \mathrm{wt} \%$ TriEDMA, heated at $100^{\circ} \mathrm{C}(60 \mathrm{~s})$, swollen in acetone; scanned area $15.6 \times 15.6 \mu \mathrm{m}^{2}$

the blends studied, the same results were obtained independent of the probing force and the probed area, indicating the real nature of the observed 'cavities'. Furthermore, additional evidence can be presented to confirm the interpretation offered above for the elastomer-coagent blend micrographs.

In our study on the mechanism of peroxide vulcanization in the presence of different coagents ${ }^{3}$, we proposed the quantitative covalent coupling of the coagent to the elastomer via a graft polymerization of the vinyl end groups, initiated by EPM macroradicals, thus forming crosslinked coagent domains, incorporated into the EPM matrix.

AFM microscopy supported this proposed mechanism, which implies the dispersion of the elastomer-coagent compound, by the following experiment. A compound sample was prepared, containing $2 \mathrm{wt} \%$ dicumylperoxide and $3 \mathrm{wt} \%$ TriEDMA. The heated sample $\left(100^{\circ} \mathrm{C}, 60 \mathrm{~s}\right)$ was immersed in acetone $(30 \mathrm{~min})$, blotted free of surface fluid and analysed by AFM (Figure 4). The typical morphology is explained by swelling of crosslinked coagent domains, which are covalently bound to the
EPM matrix. The swollen coagent domains appear as bubbles on a flat elastomer matrix and give a positive representation of Figure $2 b$, where cavities can be considered as a negative image of the coagent phase. This provided ultimate proof of the dispersed nature of the elastomer-coagent blends.

These studies on the phase separation of the elastomer-coagent blends were extended by using various coagents. Especially strong effects on the surface topography were visualized when the coagents contained methacrylic groups. Thus, AFM can be used advantageously to establish the heterogeneity of relatively soft materials, such as unvulcanized EPM-coagent blends. Moreover, the technique can serve to provide surface images of swollen samples.

\section{ACKNOWLEDGEMENTS}

The authors thank Mr I. M. Wienk for preparing the polysulfone membranes.

\section{REFERENCES}

Hofmann, W. Kautschuk Gummi Kunstst. 1987, 40, 308

2 Endstra. W. C. "Various aspects of ethylene propylene based polymers', Proc. Int. Conf. 16-17 April 1991, Leuven, Belgium Dikland, H. G. PhD Thesis University of Enschede, 1992

4 Patil, R., Kim, S.-J., Smith, E. and Reneker, D. H. Polym. Commun. 1990, 31, 455

5 Magonov, S. N., Kempf, S., Kimmig, M. and Cantow, H.-J Polym. Bull. 1991, 26, 715

6 Hansma, H., Motamedi, F., Smith, P. and Hansma, P. K. Polymer 1992, 33, 647

7 Dietz, P., Hansma, P. K., Inacker, O., Lehmann, H. D. and Herrmann, K.-H. J. Membr. Sci. 1992, 65, 101

8 Sheiko, S. S., Magonov, S. N. and Möller, M. Polym. Prepr. 1992,33 (1), 788

9 Annis, B. K., Schwark, D. W., Reffner, J. R., Thomas, E. L. and Wunderlich, B. Makromol. Chem. 1992, 193, 2589 